\title{
Accelerated transformation of 1,3-dichloropropene in loamy soils
}

\author{
J. H. SMELT, W. TEUNISSEN, S. J. H. CRUM \& M. LEISTRA \\ Institute for Pesticide Research (IOB), P.O. Box 650, NL 6700 AR Wageningen, Nether- \\ lands
}

Received 9 June 1988; accepted 10 March 1989

\begin{abstract}
Inadequate nematode control on some loamy soils after fumigation with 1,3-dichloropropene prompted further study of transformation in these soils. The rate of transformation of $(Z)$ - and $(E)$-1,3-dichloropropene was measured in moist soils incubated at $15^{\circ} \mathrm{C}$ in fumigant-tight systems. In six loamy soils, transformation was gradual and pseudo first-order during 3 to 6 days but thereafter it was very fast. At an initial content in dry soil of $62-80 \mathrm{mg} \mathrm{kg}$, the remaining amounts were less than $0.2 \%$ of the dose after a week. The greatly accelerated transformation after a short lag time suggests that the soils contained micro-organisms that can transform 1,3-dichloropropene effectively. The fast transformation was measured in soil from fields once or twice fumigated previously as well as from fields never treated. In one of these loamy soils, a fast transformation (less than $0.2 \%$ remaining after 7 days) was measured at initial contents of $3.7,18$ and $92 \mathrm{mg} \mathrm{kg}^{-1}$. But when the initial content was $470 \mathrm{mg}$ $\mathrm{kg}^{-1}$, the transformation rate was drastically suppressed (half-life 33 days). In another loamy soil, which showed no accelerated transformation patterns, the pseudo half-lives substantially increased from 4.3 to 36 days when the initial content of 1,3-dichloropropene was raised from 3.7 to $470 \mathrm{mg} \mathrm{kg}^{-1}$.
\end{abstract}

Keywords: biotransformation, dichloropropenes, fumigant isomers

\section{Introduction}

In the Netherlands, there is increasing interest in fumigating heavier loamy soils with low doses (about $1501 \mathrm{ha}^{-1}$ ) 1,3-dichloropropene (1,3-D) to reduce injury of crops by soil nematodes. However, it was difficult to obtain adequate control of potato cyst nematode (Globodera rostochiensis and $G$ pallida) in field trials with loamy soils (Been \& Schomaker, 1987; Plant Protection Service, unpublished results). One cause for the insufficient nematode control on heavier loamy soils may be that it is difficult to get these soils in the proper structural condition for soil fumigation. Another cause could be the high transformation rates of $1,3-\mathrm{D}$ in loamy soils if compared to sand and peaty soils (van Dijk, 1974; van Dijk, 1980; Roberts \& Stoydin, 1976). The combination of high transformation rates with low diffusion rates, especially at the higher soil moisture contents, will result in low concentration-time 
products at some distance from the injection sites (Leistra, 1972).

After fumigation of heavier loamy soils, the top layers showed very low 1,3-D contents. In some fields, disappearance was distinctly faster in the second week after injection than in the first week, under fairly constant soil and weather conditions. Reducing vapour losses by plastic sheeting did hardly influence the disappearance (Smelt et al., 1989). These findings suggested that disappearance of the 1,3-D was mainly due to fast transformation.

Observations from field studies prompted further study on transformation rates under laboratory conditions, particularly in loamy soils. These rates were also needed to compute the concentration-time products of the fumigant in the soil profiles with simulation models as used by Leistra (1972). Such computations can be helpful in interpretation of the inadequate nematode kill as found in field trials (Been \& Schomaker, 1987).

\section{Materials and methods}

\section{Collection of soils}

Soil was collected from 11 arable fields, listed in Table 1. Ten fields were in East Flevoland and the North-East Polder, which are both young polders reclaimed from the lake IJsselmeer. Loamy soils are the most common types in these polders. One soil was collected from a field in the reclaimed peat area in the province of Drenthe (Table 1, field AZ). The four fields, coded KD 35 to KD 38, are fields of the Kandelaar Experimental Farm in an area of $1.2 \mathrm{~km} \times 1.0 \mathrm{~km}$ in East Flevoland. The history of fumigation of the fields before sampling is given in Table 2 .

At 15 to 20 sites on each field, soil was collected from the arable layer (to $0.25 \mathrm{~m}$

Table 1. Composition, $\mathrm{pH}$ values, and moisture contents of soils at sampling.

\begin{tabular}{lllllll}
\hline Field & \multicolumn{2}{l}{ Mass fraction } & & $\begin{array}{l}\mathrm{pH} \\
(\mathrm{KCl})\end{array}$ & $\begin{array}{l}\text { Moisture } \\
\text { content } \\
\left(\mathrm{kg} \mathrm{kg}^{-1}\right)\end{array}$ \\
\cline { 2 - 4 } $\begin{array}{l}\text { Organic } \\
\text { matter }\end{array}$ & $\begin{array}{l}\text { Clay } \\
(\%)\end{array}$ & $\begin{array}{l}\text { Silt } \\
(\%)\end{array}$ & $\begin{array}{l}(2-50 \mu \mathrm{m}) \\
(\%)\end{array}$ & $\begin{array}{l}\mathrm{CaCO}_{3} \\
(\%)\end{array}$ & & \\
KD 35 & 3.5 & 37 & 50 & 9.1 & 7.2 & \\
KD 36 & 3.5 & 43 & 49 & 9.0 & 7.4 & 0.30 \\
KD 37 & 3.4 & 46 & 50 & 11.1 & 7.5 & 0.32 \\
KD 38 & -6 & - & - & - & - & 0.26 \\
SG & 4.2 & 36 & 45 & 8.0 & 7.3 & 0.32 \\
WD & 2.8 & 31 & 54 & 9.8 & 7.3 & 0.26 \\
TP & 2.5 & 30 & 59 & 10.1 & 7.4 & 0.26 \\
PA & 3.0 & 25 & 32 & 8.1 & 7.5 & 0.28 \\
DW 7 & 1.4 & 6.3 & 9 & 3.5 & 7.5 & 0.16 \\
DW 9 & 1.8 & 7.2 & 13 & 4.2 & 7.5 & 0.17 \\
AZ & 11.0 & 2.0 & - & 0.5 & 5.2 & 0.22 \\
\hline
\end{tabular}

${ }^{a}$ Field on the same farm and with similar composition as KD 35, 36, 37.

${ }^{\mathrm{b}}$ Not measured. 
Table 2. History of 1,3-dichloropropene applications (about $1501 \mathrm{ha}^{-1}$ ) on the fields.

\begin{tabular}{lll}
\hline Field & $\begin{array}{l}\text { Number of } \\
\text { applications }\end{array}$ & $\begin{array}{l}\text { Period between last application } \\
\text { and sampling (years) }\end{array}$ \\
KD 35 & 0 & - \\
KD 36 & 0 & - \\
KD 37 & 1 & 2 \\
KD 38 & 0 & - \\
SG & 2 & - \\
WD & 0 & 4 \\
TP & 1 & 9 \\
PA & $1^{\text {a }}$ & 0.3 \\
DW 7 & 6 & - \\
DW 9 & 0 & - \\
AZ & - b &
\end{tabular}

${ }^{a}$ Six applications with metham sodium (rate of a.i. $150 \mathrm{~kg} \mathrm{ha}^{-1}$ ) in the last 7 years.

${ }^{\mathrm{b}}$ About two applications in the last 15 years; last fumigation with metham sodium 2 years before sampling.

depth) and thoroughly mixed. About $10-\mathrm{kg}$ portions of the soils were stored in the dark at 10 to $17^{\circ} \mathrm{C}$ in plastic bags with a small opening for gas exchange. Incubations started within 1 to 11 weeks after collecting the soil.

\section{Incubation system}

In preliminary experiments, several systems were tested for loss of 1,3-D vapour. The best results were obtained with $600-\mathrm{cm}^{3}$ glass flasks closed with ground glass stoppers, placed top-down in a layer of water to prevent drying of the seal of stopper. Of a mixture of $(Z)$ - and $(E)-1,3-\mathrm{D}, 5 \mu \mathrm{l}$ was added to each of 14 flasks, which were then stored in the dark at $20^{\circ} \mathrm{C}$. Remaining masses were dissolved after rapid injection of $25 \mathrm{~cm}^{3}$ of $n$-hexane. No loss of fumigant could be detected during an incubation time up till 115 days (average recovery $93.2 \% ; s=7 ; n=14$ ).

In a parallel study, the same flasks were filled with $25 \mathrm{~cm}^{3}$ solutions of $1,3-\mathrm{D}$ in distilled water $\left(1\right.$ and $50 \mu \mathrm{g} \mathrm{cm}^{-3}$ ) and incubated in the dark at $10^{\circ} \mathrm{C}$. Flasks were extracted with $25 \mathrm{~cm}^{3}$ of hexane at intervals over a period of 40 days. A first-order disappearance, corresponding with a half-life of 53 days was measured for the two isomers at the two concentrations. This half-life is quite similar to that of 50.9 days, measured in other hydrolysis studies with 1,3-D at $10^{\circ} \mathrm{C}(\mathrm{McC}$ all, 1987). These two tests proved that the system was reliable for the transformation studies in soil.

\section{First incubation series with nine soils}

Moist soil in quantities of $100 \mathrm{~g}$ (corresponding to $76-85 \mathrm{~g}$ of dry soil) were weighed into series of 14 to 16 flasks and moisture contents adjusted, if necessary, to those of Table 1. These moisture contents were representative for field conditions during fumigation. The corresponding moisture pressures were about $-10 \mathrm{kPa}(-0.1$ bar $)$. 
A mixture of equal amounts of $(Z)$ - and $(E)-1,3-\mathrm{D}$ (99\% purity) was added with microlitre syringes to get initial contents in dry soil of 30 to $150 \mathrm{mg} \mathrm{kg}^{-1}$ for each isomer. The two isomers were added in aqueous solution $\left(0.2-2.0 \mathrm{~cm}^{3} ; 1 \mathrm{~g} \mathrm{l}^{-1}\right)$ to get initial contents less than $30 \mathrm{mg} \mathrm{kg}^{-1}$. At intervals during incubation (up to 40 days), one or two flasks were taken for extraction. The length of the intervals were adjusted to the observed rate of disappearance of the compounds.

The humic sand soil AZ was incubated with either $(Z)$ - and $(E)-1,3-D$. Six flasks for each isomer were extracted at intervals in a period of 14 days.

All incubations were done in the dark at $15( \pm 1)^{\circ} \mathrm{C}$.

\section{Second incubation series with five loamy soils and with single soil cores}

The results of the first incubations with soils collected from East Flevoland suggested a very rapid degradation of $1,3-\mathrm{D}$ by specific micro-organisms. During sample handling in the field and in the laboratory, one soil, which possibly contained these organisms, could have infected other soil samples. To exclude this possibility and to check the reproducibility of the incubation results, fresh samples were collected from fields KD 36, KD 37 and TP in January 1986. In the period between the date of collecting the soils for the first incubation series and January 1986, the field TP was again treated with Telone II (95\% 1,3-D) at $1501 \mathrm{ha}^{-1}$.

At the second sampling date, soil was also collected from the fields KD 35 and KD 38 of the Kandelaar Experimental Farm. These two fields ( 5 ha each) were chosen because they had never been treated with $1,3-\mathrm{D}$, like field $\mathrm{KD} 36$ on that same farm. In addition, 15 single soil cores, systematically distributed over an area of about 2 ha, were taken from field KD 36.

In the field, each core ( 70 to $105 \mathrm{~g}$ moist soil) was placed in a flask, which was transferred to the laboratory for incubation. This sampling was done to examine whether the rapid degrading capability, as measured in the first incubation series with this soil, was evenly spread over the field. The sampling tools were rinsed and disinfected with methanol before the next core was taken or another field was sampled. In the laboratory, the soils were prepared strictly apart and incubated as described in the previous section, with an initial content of $1,3-\mathrm{D}$ of $62-80 \mathrm{mg} \mathrm{kg}^{-1}$. Incubations started 7 days after collection of the soils.

\section{Effect of initial content on transformation rate}

The results of the first incubation series indicated that the transformation rate could depend on the initial content of 1,3-D. To study this effect in more detail, soils of fields KD 36 and KD 38 were incubated with 1,3-D at initial contents in dry soil of $3.7,18,92$ and $470 \mathrm{mg} \mathrm{kg}^{-1}$, ratio $1: 1$ for the $(Z)$ - and $(E)$-isomer. These soils were chosen because of their different properties in degrading 1,3-D. Soil KD 36 showed very fast transformation after some days, whereas KD 38 had a rather constant and moderate rate of transformation for $1,3-\mathrm{D}$. These transformation rates were measured after an initial content of about $80 \mathrm{mg} \mathrm{kg}^{-1}$ in the first and second incubation series, respectively. 


\section{Analysis}

$100 \mathrm{~cm}^{3} n$-hexane and $50 \mathrm{~cm}^{3}$ water was quickly added to the incubation flasks, which were subsequently shaken on a reciprocating shaker for $2 \mathrm{~h}$. Concentrations of $(Z)$ - and $(E)-1,3-\mathrm{D}$ in the hexane extract were measured with a Tracor 550 gas chromatograph with a ${ }^{63} \mathrm{Ni}$ electron-capture detector. The stainless steel column (length $3 \mathrm{~m}$; inner diameter $2 \mathrm{~mm}$ ) was packed with $8 \%$ Carbowax $20 \mathrm{M}$ on Anakrom ABS (particle size $0.18-0.21 \mathrm{~mm}$ ). With a nitrogen flow rate of $40 \mathrm{~cm}^{3} \mathrm{~min}^{-1}$ and a column temperature of $100^{\circ} \mathrm{C}$, the retention times of $(Z)$ - and $(E)-1,3-\mathrm{D}$ were 2.5 and $3.6 \mathrm{~min}$, respectively. Concentrations in the extracts were calculated with the external standard method based on peak heights or integrated areas obtained from 3- $\mu$ l injections of solutions of the analytical-grade isomers in hexane $\left(0.1-1.5 \mathrm{mg} \mathrm{l}^{-1}\right)$. The minimum detectabie mass in the incubation systems was $5 \mu \mathrm{g}$ for each isomer.

Recovery varied from 80 to $90 \%$ as calculated from the extracted masses after 0.02 to 1 day. The masses measured were not corrected for this recovery.

Duplicate measurements at each extraction time in general differed only a few percent, and therefore averaged. Recovered masses were given separately if they differed more than $10 \%$.

\section{Results}

\section{First incubation series with nine soils}

Plots of the extracted amounts on a log scale against time showed linear decline of the two isomers of 1,3-D in the DW 7, DW 9 and AZ soil. This suggested that firstorder kinetics could be used to describe the transformation of the compounds during incubation. The calculated pseudo first-order rate coefficients $\mathrm{k}\left(\mathrm{d}^{-1}\right)$ and the corresponding half-lives are given in Table 3 . There was no difference between the transformation rates of the $(Z)$ - and $(E)$-isomers in the AZ soil (single isomers applied), nor in the two DW soils in which the isomers were incubated together. In the

Table 3. First-order rate coefficients $(k)$ and corresponding half-lives for transformation of $(Z)$ - and (E)-1,3-dichloropropene in three moist soils at $15^{\circ} \mathrm{C}$.

\begin{tabular}{|c|c|c|c|c|c|}
\hline \multirow[t]{2}{*}{ Soil } & \multirow{2}{*}{$\begin{array}{l}\text { Initial } \\
\text { content } \\
\left(\mathrm{mg} \mathrm{kg}^{-1}\right)\end{array}$} & \multicolumn{2}{|c|}{$(Z)$-isomer } & \multicolumn{2}{|c|}{$(E)$-isomer } \\
\hline & & $k\left(d^{-1}\right)$ & half-life (d) & $k\left(d^{-1}\right)$ & half-life (d) \\
\hline $\mathrm{AZ}$ & $\begin{array}{l}15 \\
15 \\
65 \\
93\end{array}$ & $\begin{array}{l}0.039 \\
0.021\end{array}$ & $\begin{array}{l}18 \\
33\end{array}$ & $\begin{array}{l}0.038 \\
0.022\end{array}$ & $\begin{array}{l}18 \\
32\end{array}$ \\
\hline DW 7 & $145^{\mathrm{a}}$ & 0.044 & 16 & 0.038 & 18 \\
\hline DW 9 & $145^{\mathrm{a}}$ & 0.07 & 10 & 0.056 & 12 \\
\hline
\end{tabular}

${ }^{\text {a }}$ For each isomer, total content of $1,3-\mathrm{D} 290 \mathrm{mg} \mathrm{kg}^{-1}$. 
$\mathrm{AZ}$ soil, the transformation was distinctly faster at the lower initial contents than at the higher. This could indicate an effect of the content on the transformation rate.

The recovered amounts of $(Z)$ - and $(E)-1,3-\mathrm{D}$ in the six loamy soils KD $36, \mathrm{KD}$ 37, TP, WD, SG and PA differed less than $10 \%$ on each sampling date. This means that there was also no difference in transformation rate between the isomers in these soils. Therefore the amounts recovered of the two isomers were averaged for each extraction date and the mass fraction remaining from the dose $(\%)$ were plotted on a log scale against time (Fig. 1).

At total initial contents of $(Z)$ - and $(E)-1,3-\mathrm{D}$ between 62 and $80 \mathrm{mg} \mathrm{kg}^{-1}$, the disappearance in these six loamy soils was quite similar. During the first 3 to 6 days, transformation was slow, but from day 6 on the amounts recovered were very low and mostly below detection limit (e.g. $0.2 \%$ of the dose). The greatly accelerated transformation rates after a short lag time suggested the presence of micro-orga-
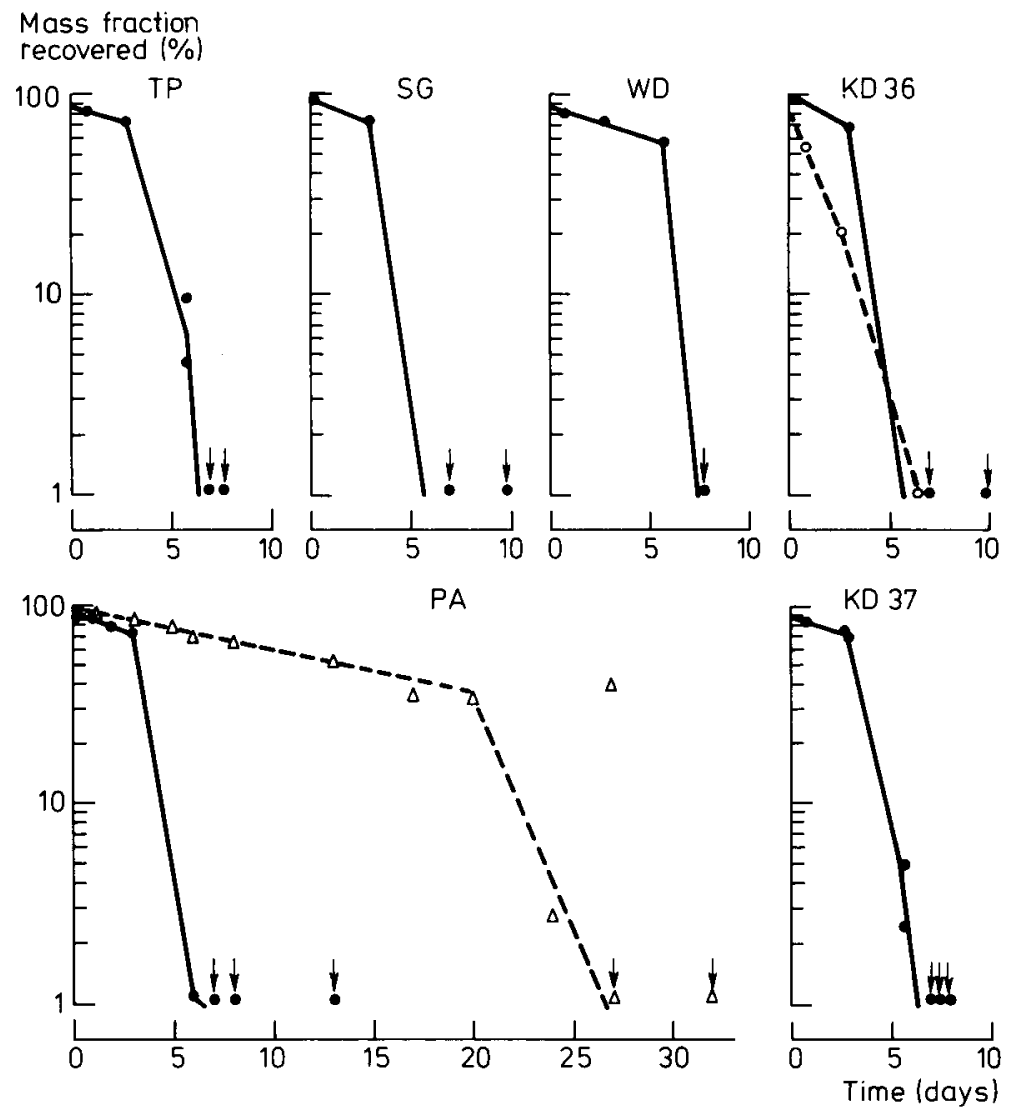

Fig. 1. Transformation of $(Z)$ - and $(E)$-1,3-dichloropropene (1:1) in six loamy soils at $15^{\circ} \mathrm{C}$. Initial content in dry soil of $(Z)+(E): \bigcirc--\bigcirc 8 \mathrm{mg} \mathrm{kg}^{-1},-62-80 \mathrm{mg} \mathrm{kg}^{-1}, \triangle-\cdots \triangle 300 \mathrm{mg} \mathrm{kg}^{-1}$, $\downarrow=<0.2 \%$ remaining. 
nisms which could quickly build up an effective transformation capacity.

A possible dose-dependent transformation rate was observed with the incubation at two initial contents in the soils KD 36 and PA (Fig. 1).

\section{Second incubation series with five loamy soils and with single soil cores}

The transformation patterns of the two isomers in these second incubation series in fresh soil of the fields KD 36, KD 37 and TP are presented in Fig. 2. In general, results were similar to those measured in the first incubation series (Fig. 1). In the second incubation series, the lag period before the fast transformation started seemed somewhat longer in the KD 37 soil and shorter in the TP soil. As extraction intervals were comparatively long ( 1 to 2 days) and the number of extractions limited, these small differences in lag period may not be material.

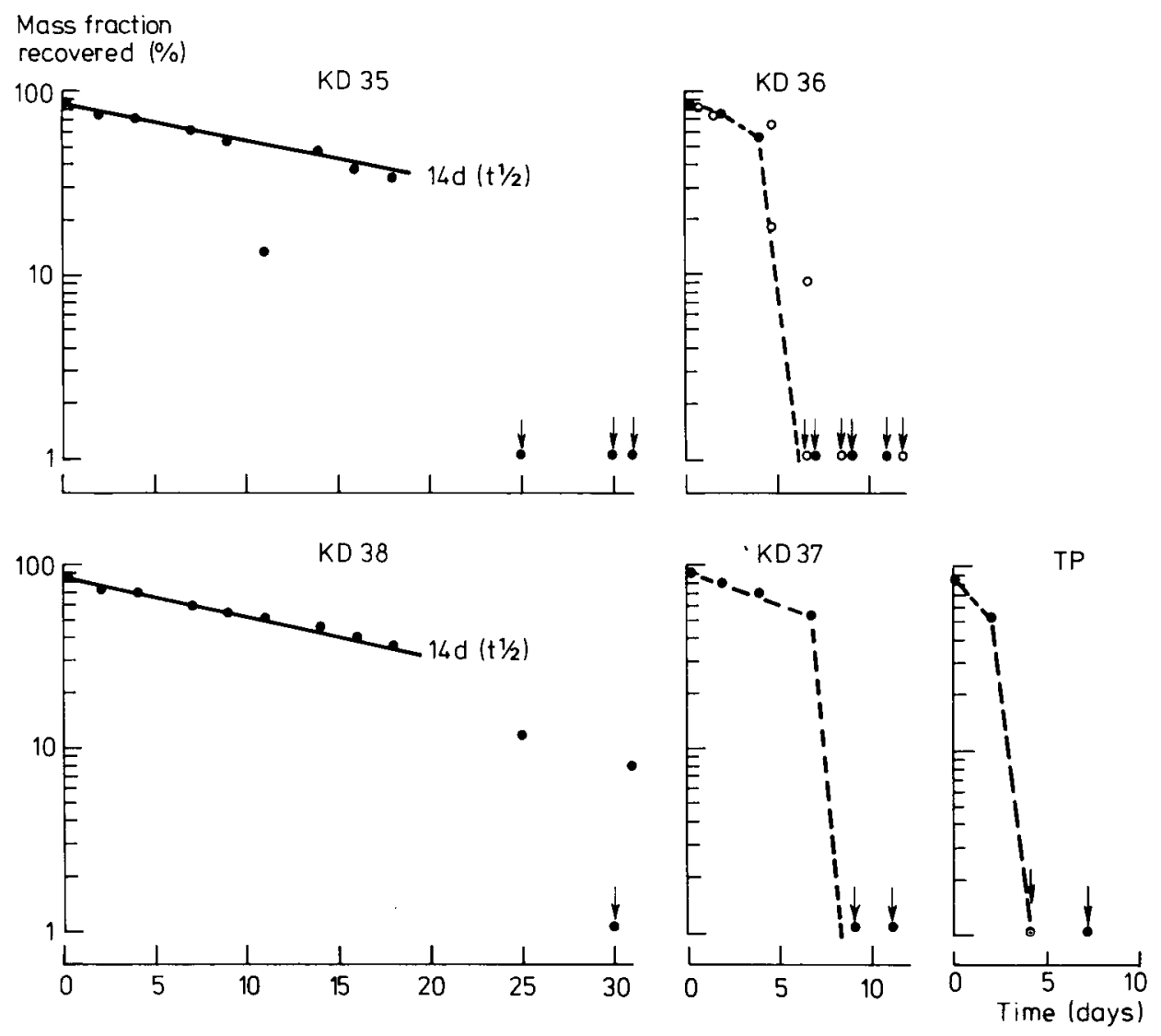

Fig. 2. Transformation of $(Z)$ - and $(E)$-1,3-dichloropropene (1:1) with the second incubation series in fresh soil samples at $15{ }^{\circ} \mathrm{C}$. Initial content of $(Z)+(E) 62-80 \mathrm{mg} \mathrm{kg}^{-1}$ dry soil. $\mathrm{in}$ mixed soil, $\bigcirc$ in single soil cores, $\downarrow=<0.2 \%$ remaining. 
The pattern of disappearance in the separately collected and incubated soil cores of field KD 36 was similar to that in portions of the mixed soil sample. This suggests that the capacity for fast transformation was evenly spread over the sampled area ( 2 ha) in this field.

The transformation of 1,3-D in the soil samples of the fields KD 35 and KD 38 could be described by first-order kinetics (Fig. 2, half-life $14 \mathrm{~d}$ ) during the first three weeks. But afterwards, an accelerated transformation was measured also in the two soils that had never been fumigated before.

\section{Effect of initial content on transformation}

At an initial content in dry soil of $3.7 \mathrm{mg} \mathrm{kg}^{-1}$, transformation was about nine times
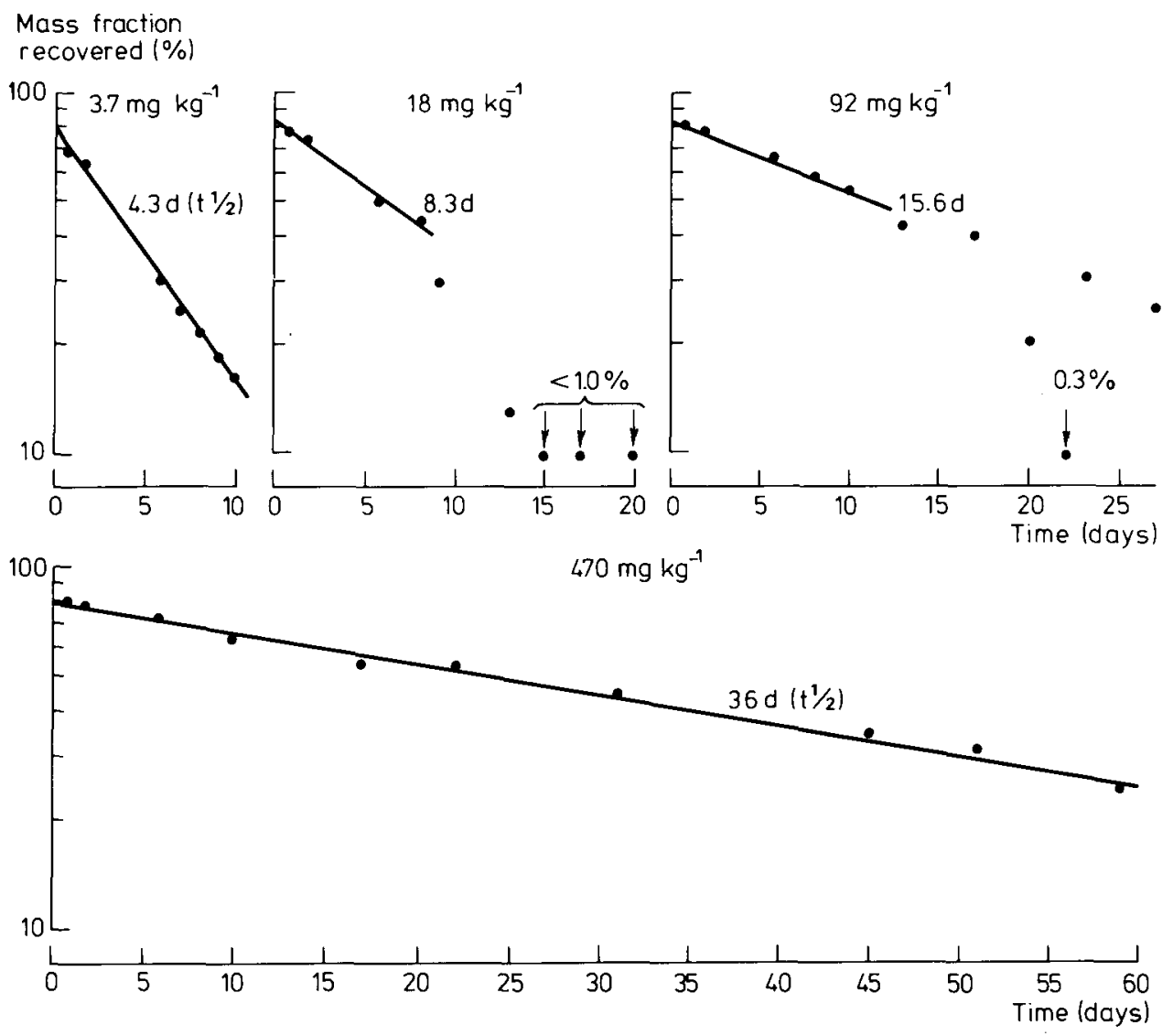

Fig. 3. Effect of initial content of 1,3-dichloropropene on rate of transformation in soil of field KD 38 . Initial content of $(Z)+(E)$ in dry soil $3.7,18,92$, and $470 \mathrm{mg} \mathrm{kg}^{-1}$. Temperature $15{ }^{\circ} \mathrm{C}$. — calculated regression line. 
as fast as that with $470 \mathrm{mg} \mathrm{kg}^{-1}$ in soil of field KD 38 (Fig. 3). At initial contents of 18 and $92 \mathrm{mg} \mathrm{kg}^{-1}$, the masses recovered were somewhat irregular after 9 days of incubation and sometimes they were very low. Therefore, pseudo first-order rate constants and corresponding half-lives were calculated only for the first 8 or 10 days, respectively (Fig. 3). The irregular decrease after prolonged incubation suggests that microbes involved in transforming the 1,3-D developed differently in some incubation flasks. This potential for accelerated transformation after a longer incubation time was already measured in the incubation with this soil described in the previous section (Fig. 2).

Dose-dependent transformation of 1,3-D in the soil of field KD 36, with the fast transformation potential, is presented in Fig. 4. For corresponding initial contents
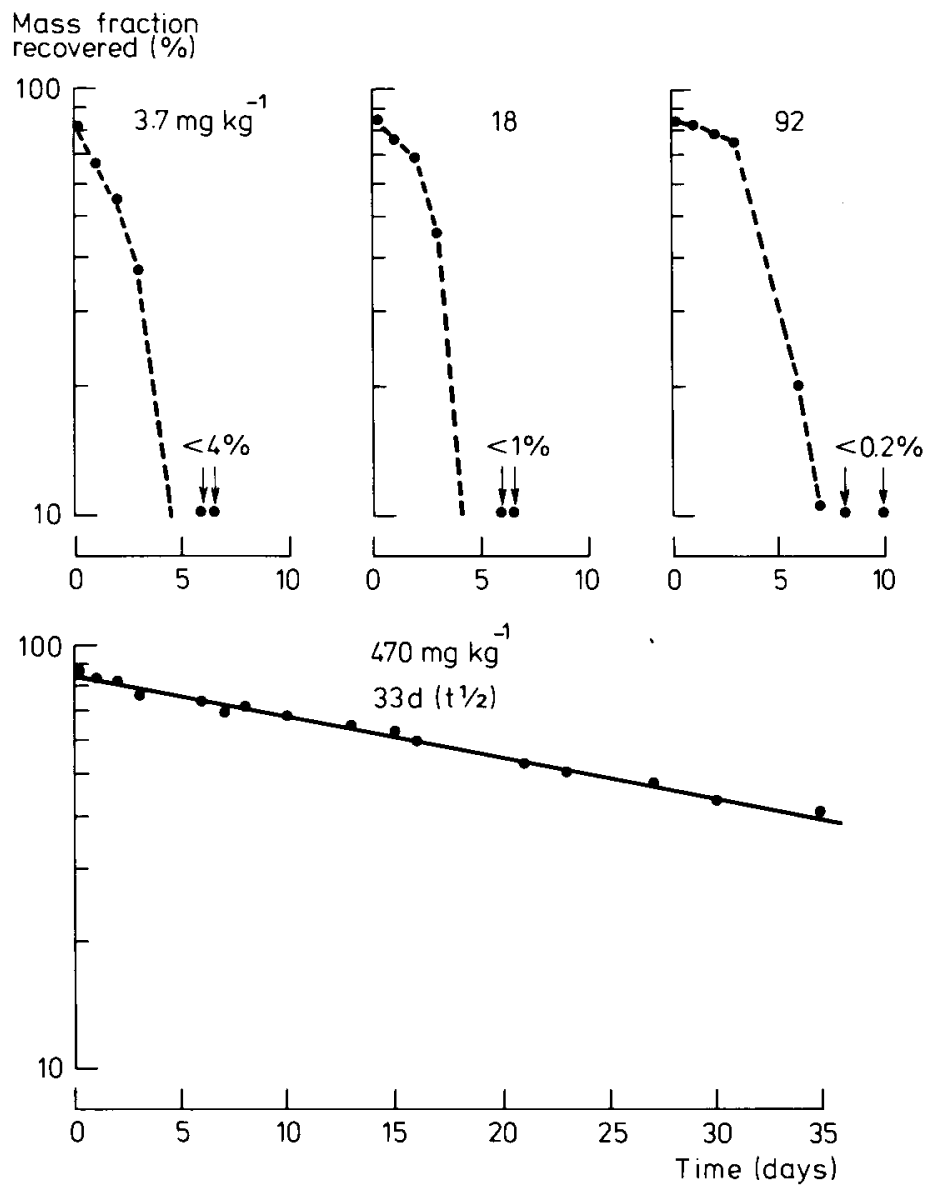

Fig. 4. Effect of initial content of 1,3-dichloropropene on rate of transformation in soil of field KD 36 . Initial content of $(Z)+(E)$ in dry soil $3.7,18,92$, and $470 \mathrm{mg} \mathrm{kg}^{-1}$ soil. Temperature $15^{\circ} \mathrm{C}$. calculated regression line,--- approximated decrease. 
the recovery of 1,3-D was almost the same as in soil from KD 38 during the first 3 to 4 days of incubation. Thereafter a very fast transformation started, which resulted in no detectable masses after 7 days, except for the initial content of $470 \mathrm{mg} \mathrm{kg}^{-1}$ in which the rate of transformation remained constant (half-life $33 \mathrm{~d}$ ).

\section{Discussion and conclusions}

In earlier studies on the rate of transformation of 1,3-D in soils (van Dijk, 1974; van Dijk, 1980; Roberts \& Stoydin, 1976), no accelerated transformation after a certain lag time was reported. However, van Dijk $(1974,1980)$ noted that the half-lives were approximate values for some of his incubations, so the pattern seemed to deviate from first-order. Repeated application of many pesticides may lead to enhanced rates of biodegradation in soil by microbial adaptation (Kaufman et al., 1984; Kearney \& Kellog, 1985). In the present study, however, rapid biodegradation was already measured in soils treated only once or twice as well as in soils never treated before. On the contrary, no enhanced degradation was measured in soil of field DW 7 (Table 3) with six preceding field applications. However, in that incubation the high initial content of $290 \mathrm{mg} \mathrm{kg}^{-1}$ (half of each isomer) may have been toxic to the micro-organisms. The finding that an initial content of $470 \mathrm{mg} \mathrm{kg}^{-1}$ suppresses the fast biotransformation that occurs at lower initial contents in soil KD 36 supports this assumption (see Fig. 4).

The transformation of 1,3-D in the five loamy soils in the first incubation series was similar to that in the second series with soil samples collected three months later. In soil from field KD 36, transformation in mixed soil and in single soil cores was also identical. So the time of collection and the handlings to prevent contamination of the soil samples at the second date did not have much effect.

The general presence of micro-organisms capable of transforming 1,3-D at a high rate in the loamy soils of East Flevoland is remarkable. The same holds for the existence of fields with great differences in transformation rates in a restricted area of even one farm ( $120 \mathrm{ha}$ ), despite the same crop rotation and other agricultural practices. The causes and general occurrence of the fast biotransformation capability are interesting points for further research. They are also of economic interest because enhanced transformation rates can considerably reduce the effects of a soil fumigation against soil-borne pests.

The effect of comparatively small differences in the initial content in the soils on transformation rate is also remarkable. Van der Pas \& Leistra (1987) also measured a considerably faster transformation of the two isomers of 1,3-D at a total initial content of $24 \mathrm{mg} \mathrm{kg}^{-1}$ than at $124 \mathrm{mg} \mathrm{kg}^{-1}$ in three sandy soils. In other experiments (van Dijk, 1974; van Dijk, 1980; Roberts \& Stoydin, 1976) the effect of dose was not studied. If this effect of initial content on transformation rate is universal, one should take this into account when results of different incubations are compared. The effect of the content on the transformation rate indicates that the reaction rates are not real first-one. The approximated half-lives are thus pseudo firstorder. Further research is needed to study the effect of initial content on transformation of this fumigant in more detail. 
In a computation model simulating the behaviour of 1,3-D in soils, Leistra (1971, 1972) assumed that the transformation rate was independent of the content in soil. After injection, contents vary considerably in time and with depth in the soil matrix. Introduction of a content-dependent transformation rate as a function of fumigant content in soil may be necessary to give a more accurate description of the fumigant behaviour in soil, particularly for longer periods.

\section{References}

Been, T. H. \& C. H. Schomaker, 1987. Fumigation of marine-clay soils infested with potato cyst nematodes. In: N. E. Fold $\varnothing$, Sv. E. Hansen, N. K. Nielsen \& R. Rasmussen (Eds), Proceedings of the 10th Triennial Conference of the European Association for Potato Research, Aalborg (Denmark), p. 410411.

Dijk, H. van, 1974. Degradation of 1,3-dichloropropenes in the soil. Agro-Ecosystems 1: 193-204.

Dijk, H. van, 1980. Dissipation rates in soil of 1,2-dichloropropane and 1,3- and 2,3-dichloropropenes. Pesticide Science 11: 625-632.

Kaufman, D. D., Y. Katan, D. F. Edwards \& E. G. Jordan, 1985. Microbial adaptation and metabolism of pesticides. In: J. L. Hilton (Ed), Agricultural Chemicals of the Future, p. 437-451. Rowman and Allanheld, Totowa, New Yersey.

Kearney, P. C. \& S. T. Kellogg, 1985. Microbial adaptation to pesticides. Pure and Applied Chemistry 57: $389-403$.

Leistra, M., 1971. Diffusion of 1,3-dichloropropene from a plane source in soil. Pesticide Science 2: 7579.

Leistra, M., 1972. Diffusion and adsorption of the nematicide 1,3-dichloropropene in soil. Doctoral thesis, Wageningen Agricultural University, $105 \mathrm{pp}$.

McCall, P. J., 1987. Hydrolysis of 1,3-dichloropropene in dilute aqueous solution. Pesticide Science 19: 235-242.

Van der Pas, L. J. T. \& M. Leistra, 1987. Movement and transformation of 1,3-dichloropropene in the soil of flower-bulb fields. Archives of Environmental Contamination and Toxicology 16: 417-422.

Roberts, F. R. \& G. Stoydin, 1976. The degradation of $(Z)$ - and (E)-1,3-dichloropropenes and 1,2-dichloropropane in soil. Pesticide Science 7: 325-335.

Smelt, J. H., M. Leistra, S. J. H. Crum \& W. Teunissen, 1989. Distribution and dissipation of 1,3-dichloropropene after injection in structured loamy soils. Acta Horticulturae (in press). 